\title{
Migration Pattern of Cementless Press Fit Cups in the Presence of Stabilizing Screws in Total Hip Arthroplasty
}

\author{
C. Zilkens ${ }^{1}$, S. Djalali1, B. Bittersohl1 ${ }^{1}$, T. Kälicke², C. N. Kraft ${ }^{3}$, R. Krauspe ${ }^{1}$, M. Jäger ${ }^{1}$ \\ ${ }^{1}$ Department of Orthopaedic Surgery, Heinrich-Heine University Medical School, Duesseldorf, Germany, \\ ${ }^{2}$ Department of Orthopaedics and Traumatology, University Hospital "Bergmannsheil”, Bochum, Germany, \\ ${ }^{3}$ Department of Orthopaedic-, Trauma- and Handsurgery, Helios Clinic Krefeld, Krefeld, Germany
}

\begin{abstract}
The aim of this study was to evaluate the initial acetabular implant stability and late acetabular implant migration in press fit cups combined with screw fixation of the acetabular component in order to answer the question whether screws are necessary for the fixation of the acetabular component in cementless primary total hip arthroplasty. One hundred and seven hips were available for follow-up after primary THA using a cementless, porous-coated acetabular component. A total of 631 standardized radiographs were analyzed digitally by the "single-film-x-ray-analysis" method (EBRA). One hundred and one (94.4\%) acetabular components did not show significant migration of more than $1 \mathrm{~mm}$. Six (5.6\%) implants showed migration of more than $1 \mathrm{~mm}$. Statistical analysis did not reveal preoperative patterns that would identify predictors for future migration. Our findings suggest that the use of screw fixation for cementless porouscoated acetabular components for primary THA does not prevent cup migration.
\end{abstract}

Key words: cementless, acetabular, fixation, with screws, without screws, EBRA, Total Hip Arthroplasty

\section{INTRODUCTION}

The acetabular implant design and materials in cementless total hip arthroplasty (THA) have improved markedly over the past decades. Reduced roughness or improved polishing of the internal surface of the cup. Optimized conformity of the liner with the metal shell of the acetabular component, improved congruity of the screw heads in the acetabular shell, better liner locking mechanisms and other factors such as modification of the outer surface to promote bone ingrowth lead to an increase of the survivorship of cementless acetabular components with and without screw fixation [1-6].

Some data suggest that additional screw fixation in press-fit implants may support the initial stability and osseointegration and also prevent late migration of the acetabular component [1, 3, 7-10].

Opponents of the use of additional screws have suggested that a press-fit technique with underreaming of the acetabular socket will provide adequate initial fixation so that adjunctive screw fixation is not indi- cated and insufficient to prevent late migration [1113]. Furthermore, the screw holes may facilitate the egress of polyethylene particles through the shell and eventually cause periimplant pelvic osteolysis [3]. Avoiding screw fixation may also reduce operative time and time of revision surgery [2], implant costs [14] and prevent complications associated with screw placement such as vascular and nerve injury [7]

Evaluation of clinical (reoperations, outcome data) and radiographic parameters (osteolysis, bone loss, radiolucency, radiodensity) associated with cementless porous-coated acetabular component design and polyethylene that is sterilized in an inert environment and stored in a vacuum provided by barrier packaging should allow a more equitable study of acetabular fixation than was possible in the past.

The aim of this study was to evaluate initial acetabular implant stability and late acetabular implant migration of press fit cups with additional screw fixation of the acetabular component in order to answer the question whether screws are necessary for the fixation of the acetabular component in cementless primary THA.

A total of 631 standardized radiographs were analyzed using the "single-film-x-ray-analysis" digital method (Einzel-Bild-Röntgen-Analyse, EBRA, Institute of Geometry, University of Insbruck, Austria). This method has been validated and employed in several clinical trials during the past years [15-22].

\section{Material And Methods}

We retrospectively analyzed the data regarding 107 cementless hemispheric porous-coated acetabular components (103 primary total hip operations, 4 revision surgeries) implanted in 102 patients (66 female, 36 male patients, average age: $63.4 \pm 15.8$ years), with at least 6 months of follow-up. A total of 631 standardized radiographs were analyzed by the "single-film-xray-analysis" digital method (EBRA, i.e. Einzel Bild Roentgen Analyse)). Average follow-up was $2.6 \pm 1.7$ years after surgery. Exclusion criteria included absence of at least 4 standing a.p. pelvic x-rays during routine clinical and radiographic follow-up and revision total hip operations.

The reason for 103 primary total hip arthroplasty (THA) was primary osteoarthritis, posttraumatic 


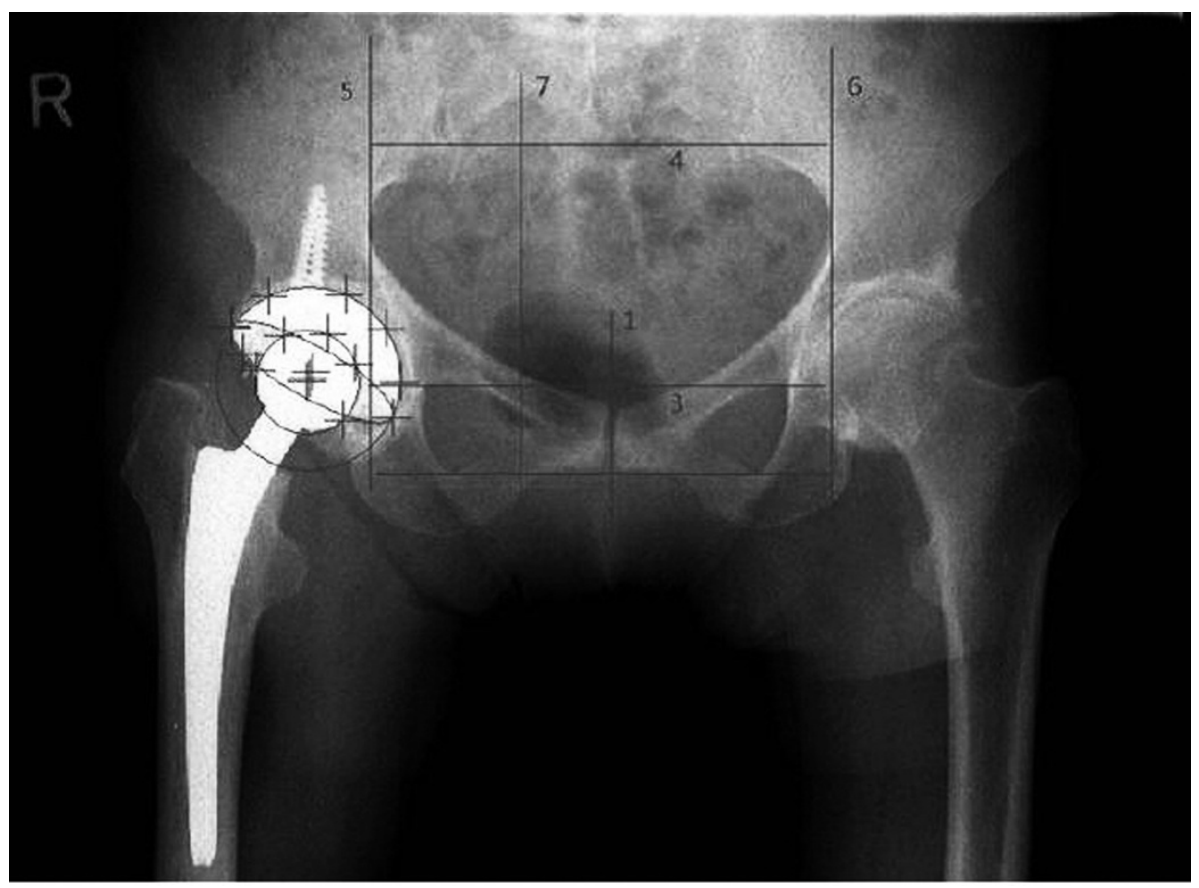

Fig. 1. Example of EBRA analysis of an a.p. pelvic film with determination of cup and head position. The numbers indicate the order in which the tangent lines to the bony reference points were drawn. arthritis or dysplasia osteoarthritis in $84(81.5 \%)$ cases, femoral head necrosis in $16(15.5 \%)$ cases, and femoral neck fracture in $3(2.9 \%)$ cases. Four revision THA's were performed due to aseptic cup loosening $9.2 \pm 4.9$ years (range $1.8-12.0$ years after primary total hip operation.

Two different porous-coated acetabular components (Duraloc, $\mathrm{n}=33$, Alpha Lock Plus, $\mathrm{n}=74$ ) were evaluated in this study. The Duraloc cup (DePuy Orthopedics, Johnson \& Johnson, Warsaw, USA) is a modular, second-generation porous-coated socket with a ring locking mechanism. The Duraloc cups used in this series were the Duraloc sector ( 3 holes) and the Duraloc 1200 series (a multihole component). The Alpha Lock Plus (Corin Group PLC, Cirencester, $\mathrm{UK}$ ) cup is a porous-coated cup with a pore size of 50 to $100 \mu \mathrm{m}$ and an additional coating of calcium-phosphate. The cup has 5 holes that can be used to place a screw or filled with a hole eliminator. The threaded insertion hole at the apex of the hemisphere can also be filled with a central hole eliminator.

The cup inlay was a standard $0^{\circ}$ polyethylene inlay (XLPE of DePuy Orthopedics or UHMWPE of Corin). Eighty-six percent of all operations were performed by two of us (RK., MJ.) between 2001 and 2007 using a standarized Bauer/Hardinge lateral approach.

Radiographic evaluation included a standing anterior/posterior radiograph of the pelvis centred on the pubic symphysis with inclusion of the proximal part of the femur and distal to the tip of the femoral stem. Postoperative gaps, radiolucent lines, bone loss, osteolytic lesions and radiodensities were identified and followed on sequential radiographs to detect progressive lesions noted in the 3 acetabular zones of DeLee and Charnley [23].

EBRA-analysis was performed by one independent observer (SD.) according to the software designer's instructions: a series of at least 4 comparable pelvic films is necessary for the analysis. By use of a corre- sponding comparability algorithm, unsuitable projections are excluded from the analysis. The comparability limit required for the requested accuracy is set at 3 $\mathrm{mm}$ as standard, corresponding to a measurement accuracy of $1 \mathrm{~mm}$ [24]. Values greater than $1 \mathrm{~mm}$ are assessed as significant for analysis of horizontal migration. This applied both for positive (= lateral) and negative (= medial) migration as both migration directions were possible. For vertical migration analysis, only positive results (primal migration) of more than $1 \mathrm{~mm}$ were considered significant. The significance limit for wear of the polyethylene inserts was set as values greater than $0.5 \mathrm{~mm}$ [25]. The results were displayed with the EBRAGRAF software of the Institute of Geometry of Innsbruck University, Austria [18].

Statistical analysis was performed with the SPSS version 13.0 software (SPSS, Chicago, IL). Student's ttest was used to analyze the relationship between cup migration and the occurrence of implant associated osteolyses and other clinical, epidemiological and radiological parameters.

Patients' consent was obtained from all patients prior to the start of this retrospective study according to our institutional regulations.

\section{RESUlTs}

Average follow-up after surgery for the study cohort was $2.6 \pm 1.7$ years ( 6 months -6.9 years). Five patients died during follow-up from causes unrelated with the surgery. Four patients $(3.7 \%)$ had to undergo revision surgery: in one patient a loose cup had to be exchanged 1.8 years postoperatively, one patient had a superficial infection and underwent debridement 3 months postoperatively, one patient had recurrent joint dislocations and had an inlay and femoral head exchange 1.6 years postoperatively and another patient had polyethylene inlay wear out and received an inlay exchange. 


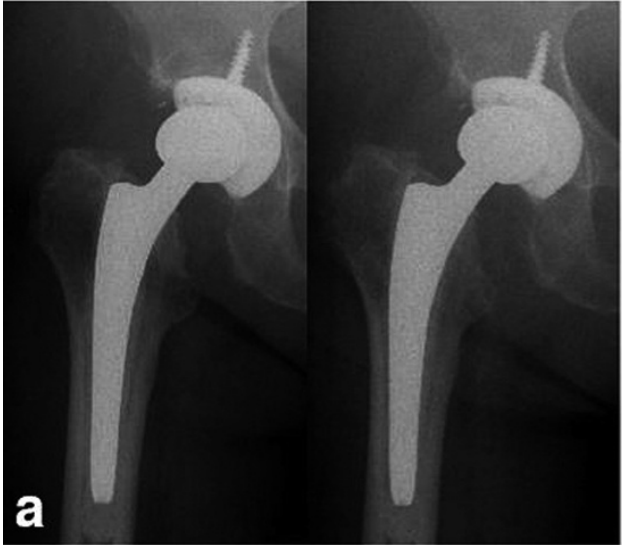

2005

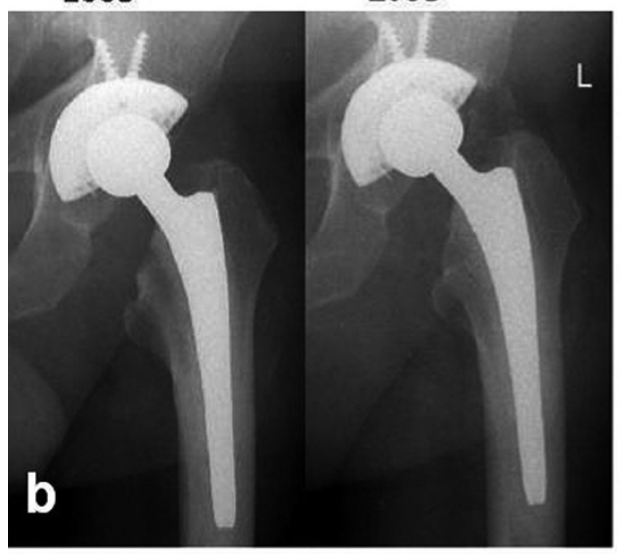

2005

2009

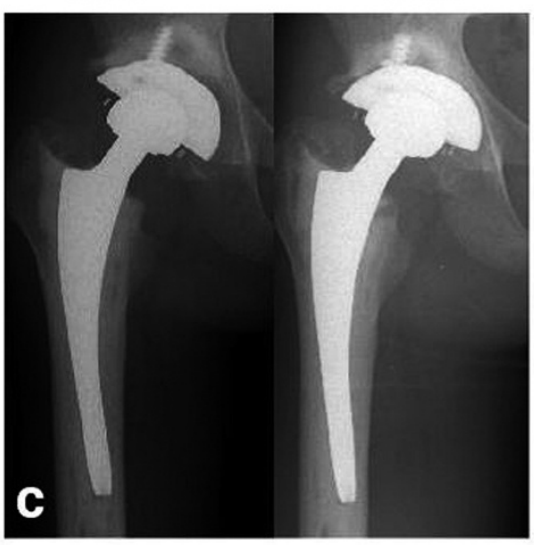

2003
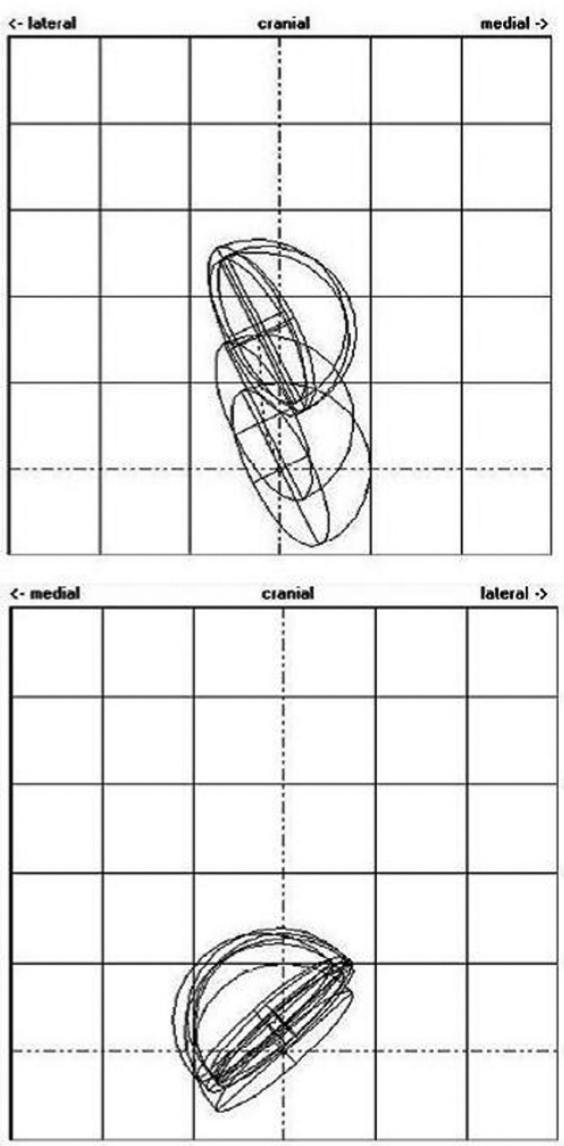

- loterel

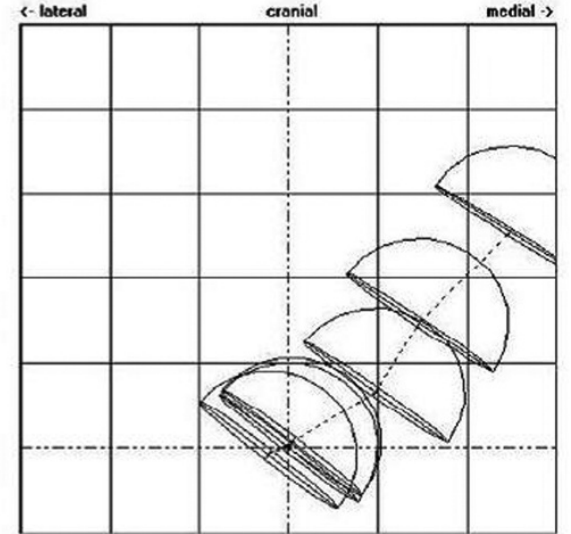

Fig. 2. Examples of three different migration patterns: $\mathrm{x}$-ray examples and underneath the year; in the corresponding SIMULGRAF diagrams, one square equals one squared millimetre. Each cup-symbol represents one measurement in a different a.p. pelvic film. a: migration diagram of a patient with $1.5 \mathrm{~mm}$ of cup migration cranially, beginning one year after implantation. Restabilisation was achieved in the further follow up of 36 months. b: migration diagram of a patient without significant migration of $<1 \mathrm{~mm}$ cranially or horizontally. Follow-up was 3.5 years. c: migration diagram of a an implant with aseptic cup loosening. Note the progressively migrating implant during 21 months of follow-up. The patient underwent revision surgery and replacement of the loosened implant.
Analysis of the conventional radiographs revealed signs of focal osteolysis in 29 cases $(27.1 \%)$. In six cases $(5.6 \%)$, radiolucent lines were visible in DeLee and Charnley [23] zones one (three implants), two (two implants) and three (in one implant). Twentythree more patients $(21.5 \%)$ developed radiographically visible bone cysts, predominantly in DeLee and Charnley zone two.

EBRA analysis could be conducted for all $107 \mathrm{im}-$ plants, so that 428 (4 films per implant) data sets could be evaluated for cup migration in the horizontal plane (x-migration) and in the vertical plane (y-migration) as well as for the assessment of change in inclination and anteversion (Fig 3). Average migration in the study group was $0.2 \pm 0.4 \mathrm{~mm}$. One hundred and one cups $(94.4 \%)$ showed no significant migration. A migration
$>1 \mathrm{~mm}$ or a change in inclination or anteversion of more than $1.7^{\circ}$ could be documented for six implants $(5.6 \%)$. The values for these six implants are shown in Table 1.

Of the six implants, three implants met the criteria of being loose, one cup was revised, the other two cups were not exchanged during the follow-up period. The other three implants restabilized spontaneously after a period of migration.

Demographic, clinical and radiological data of both, the group with significant migration $(n=6)$ and the group without significant migration $(n=101)$ is shown in Table 2 . There was no statistically significant difference within the group concerning factors that could predict a later occurrence of implant loosening. 

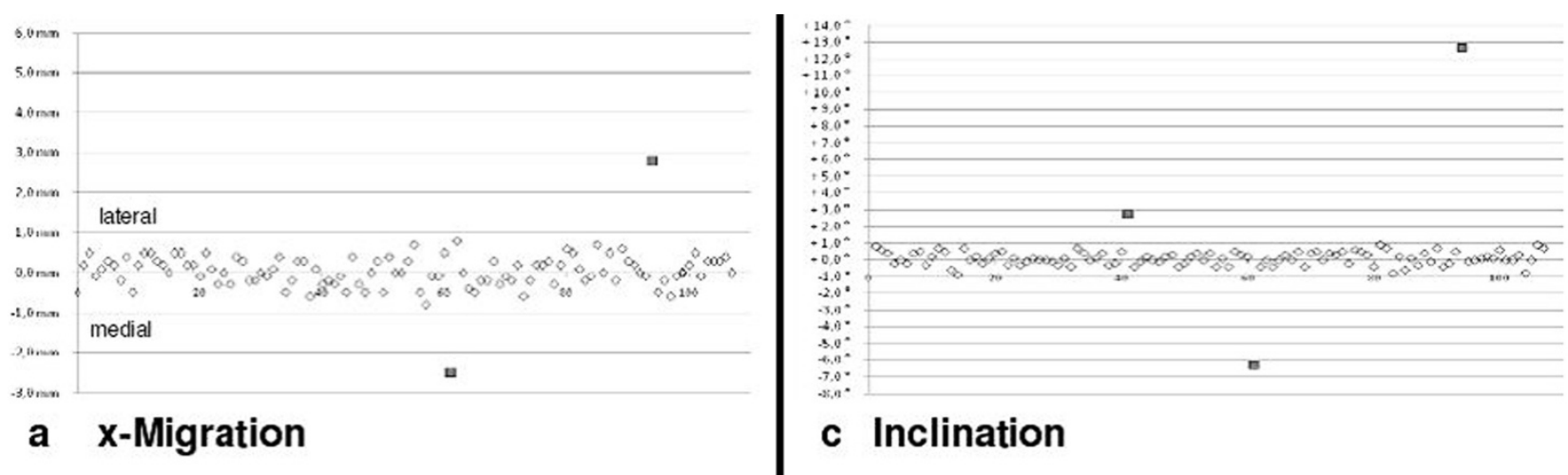

\section{c Inclination}

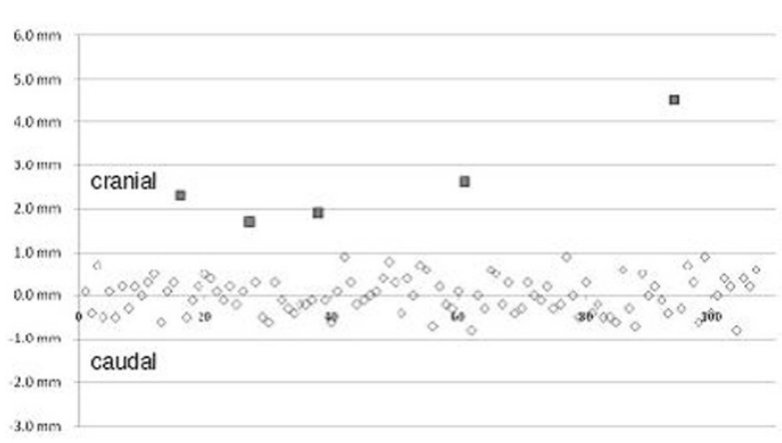

\section{b y-Migration}

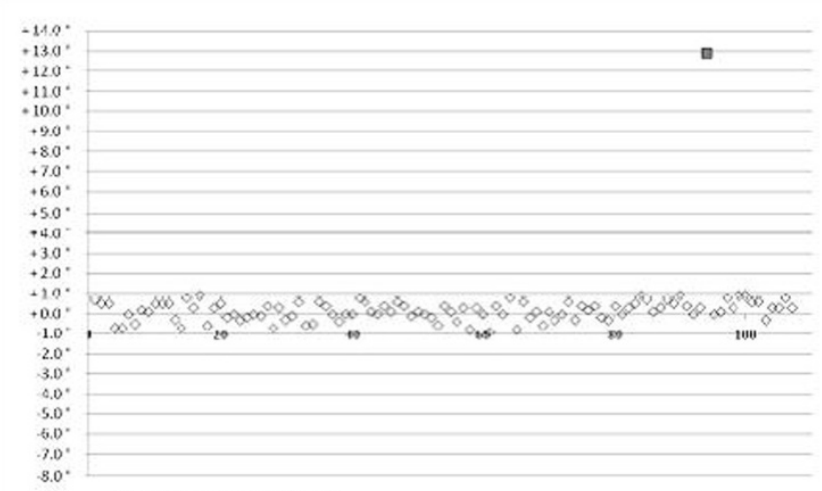

d Anteversion

Fig. 3. a: x-migration: horizontal migration of the study population. One box represents one implant. 105 implants (98.1\%) show no significant horizontal migration in contrast to two implants $(1.9 \%$, black boxes for implants no 61 and 94$)$ with significant horizontal migration. b: y-migration: vertical migration of the study population. One box represents one implant. 102 implants $(95.3 \%)$ show no significant vertical migration in contrast to 5 implants (4.7\%, black boxes for implants no 16, 27, 38, 61 and 94). c : inclination: cup inclination of the study population. One box represents one implant. 104 implants (97.2\%) show no significant change of inclination $\left(>1.7^{\circ}\right)$ in contrast to 3 implants $(2.8 \%$, black boxes for implants no 41,94 and 61$)$.d : anteversion: cup anteversion of the study population. One box represents one implant. 106 implants $(99.1 \%)$ show no significant change of anteversion $\left(>1.7^{\circ}\right)$ in contrast to 1 implant $(0.9 \%$, black box for implant no 94$)$.

Table 1. Migration pattern of the migrated cups.

\begin{tabular}{|c|c|c|c|c|c|c|}
\hline & & & Impla & mber & & \\
\hline & 17 & 27 & 38 & 41 & 61 & 94 \\
\hline $\begin{array}{l}\mathrm{x} \text {-migration } \\
(\mathrm{mm})\end{array}$ & & & & & & \\
\hline Lateral & 0.5 & 0.3 & 0.0 & 0.0 & 0.0 & 2.8 \\
\hline Medial & 0.0 & 0.0 & 0.6 & 0.2 & 2.5 & 0.0 \\
\hline $\begin{array}{c}y \text {-migration } \\
(\mathrm{mm})\end{array}$ & & & & & & \\
\hline Cranial & 2.3 & 1.7 & 1.9 & 0.1 & 2.6 & 4.5 \\
\hline Caudal & 0.0 & 0.0 & 0.0 & 0.0 & 0.0 & 0.0 \\
\hline Inclination $\left({ }^{\circ}\right)$ & & & & & & \\
\hline Post surgery & 62.3 & 64.3 & 54.1 & 38.9 & 38.9 & 57.1 \\
\hline Change & +0.0 & +0.0 & -0.3 & +2.7 & -6.3 & +12.7 \\
\hline Anteversion $\left({ }^{\circ}\right)$ & & & & & & \\
\hline Post surgery & 5.9 & 20.5 & 18.0 & 18.0 & 3.4 & 9.9 \\
\hline Change & +0.3 & +0.1 & +0.1 & +0.8 & +0.9 & +12.9 \\
\hline $\begin{array}{l}\text { Evidence of migration } \\
\text { (months) }\end{array}$ & 8 & 12 & 13 & 2 & 17 & 2 \\
\hline Time of migration & 0 & 12 & & 2 & 17 & 2 \\
\hline (months) & 14 & 6 & 13 & 4 & 21 & 10 \\
\hline Restabilisation & No & Yes & Yes & Yes & No & No \\
\hline $\begin{array}{c}\text { Follow-up } \\
\text { (months) }\end{array}$ & 14 & 36 & 25 & 69 & 21 & 10 \\
\hline
\end{tabular}


Table 2. Comparison of the two groups of cups with migration $>1 \mathrm{~mm}$ and cups with migration $<1 \mathrm{~mm}$. Note that there was no statistically significant difference between the groups.

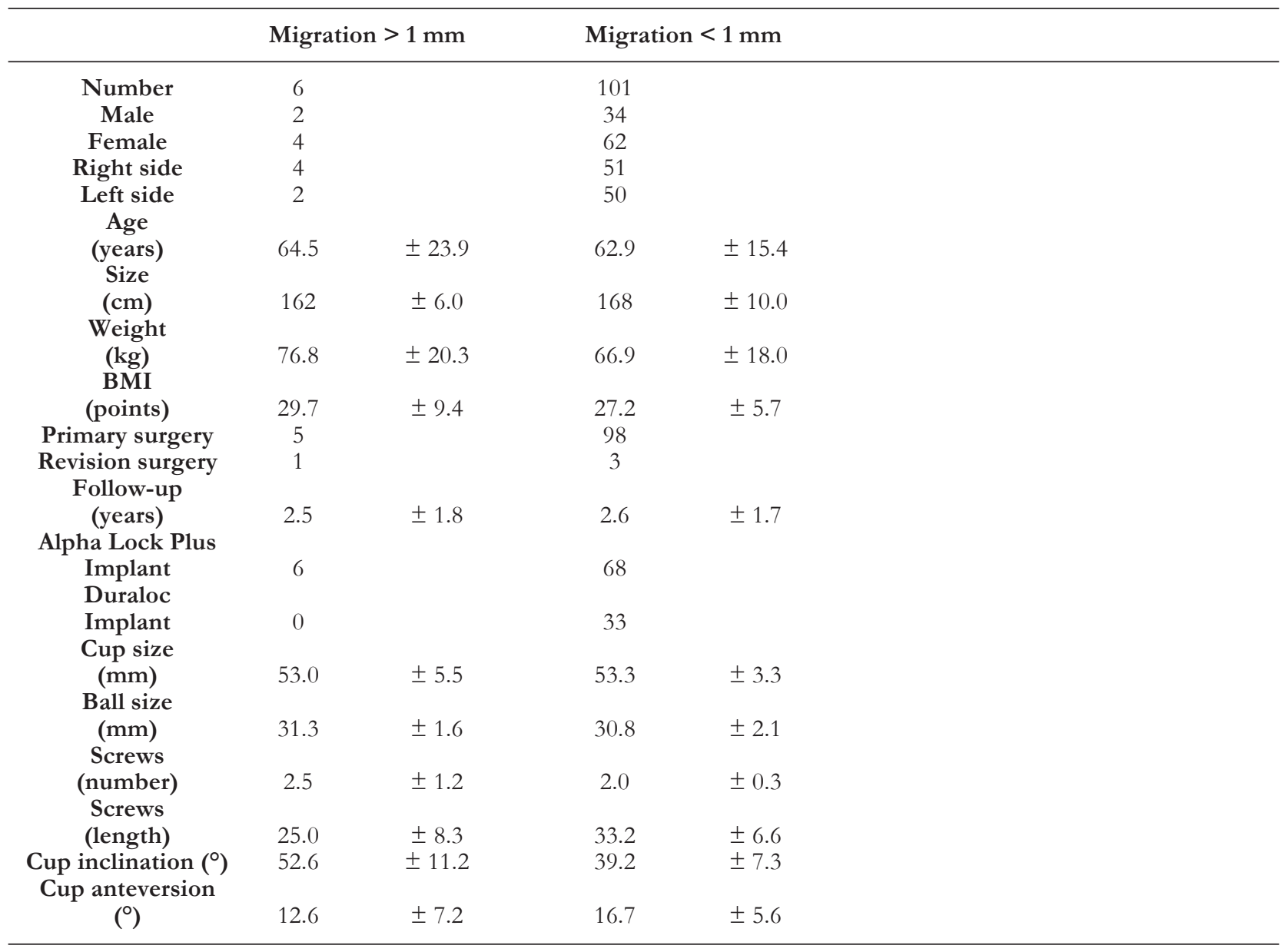

\section{Discussion}

The use of additional screw fixation in a cementless, porous-coated hemispheric acetabular press fit component is contentious. Opponents argue that screws are not only unnecessary but can be deleterious, encouraging complications such as osteolysis and aseptic loosening [26]. Recent data in large cohorts of patients show equivalent results following primary THA performed with and without screw fixation [6, 8-10, 12-13, 27]. From the biomechanical point of view, especially those screws which are not in line with the weight bearing zone of the acetabulum such as screw fixation oft the ischium or pubis are not indicated [6].

In this present study we used EBRA to investigate the migration pattern of 107 press fit cups in the presence of stabilizing screws. Six implants (5.6\%) showed a significant migration pattern, three implants displayed early migration but were considered to have re-stabilized during follow-up. Of the three definitely loose cups, one was revised and exchanged for a new press fit cementless cup.

The results of this series confirm previous reports of equivalent results of primary THA performed with porous-coated hemispheric acetabular components inserted with a $2 \mathrm{~mm}$ underreamed press-fit technique with and without screw-fixation [8-10, 12-13, 27].
For cups implanted with screws, previous reports expressed concern about polyethylene wear debris and an increased risk of osteolysis due to migration of polyethylene into the pelvis through and along the screw tracts $[2,4,11,27]$. This phenomenon was not observed in our cohort. However, the opportunity to use additive screw fixation may be indicated for selective cases. Screw fixation may be necessary whenever patients have soft bone due to osteoporosis, intraoperative fracture, a deficient acetabulum with inadequate rim coverage and inability to achieve a stable mechanical press-fit with underreaming of the acetabulum [2,23].

Although acetabular components can be successfully stabilized and fixed with or without screw fixation, laboratory studies have demonstrated that press-fit cups without screw fixation show less micro motion than cups without screw fixation [28]. In our study we could not reproduce this statement, partly because in vitro studies only evaluate a situation which corresponds to the immediate postoperative situation in vivo.

Another factor which may influence the outcome of implant loosening and migration is the locking mechanism of the polyethylene liner and the type of polyethylene ranging from UHMWPE to different grades of cross-linked varieties. The advances in the quality of polyethylene available today have muted the concerns regarding the relationship of screw fixation, polyethylene wear, and osteolysis [29]. 
The authors are aware that this study has some limitations such as a short follow-up period and a missing control group. Nevertheless we can conclude that additive screw fixation does not appear to be a major disadvantage in primary THA. At intermediate-term follow-up, cementless porous-coated press-fit acetabular fixation with screw fixation can be used successfully for primary THA.

\section{REFERENCES}

1. Roth A, Winzer T, Sander K, Anders JO, Venbrocks RA. Press fit fixation of cementless cups: how much stability do we need indeed? Arch Orthop Trauma Surg. 2006 Mar; 126(2): 77-81

2. Dorr LD, Wan Z, Cohen J. Hemispheric titanium porous coated acetabular component without screw fixation. Clin Orthop Relat Res. 1998 Jun; 351): 158-68

3. Valle AG, Zoppi A, Peterson MG, Salvati EA. Clinical and radiographic results associated with a modern, cementless modular cup design in total hip arthroplasty. J Bone Joint Surg Am. 2004 Sep; 86-A(9): 1998-2004

4. Engh CA, Hopper RH, Jr., Engh CA, Jr. Long-term porous-coated cup survivorship using spikes, screws, and press-fitting for initial fixation. J Arthroplasty. 2004 Oct; 19(7 Suppl 2): 54-60

5. Massin P, Schmidt L, Engh CA. Evaluation of cementless acetabular component migration. An experimental study. J Arthroplasty. 1989 Sep; 4(3): 245-51

6. Iorio R, Puskas B, Healy WL, Tilzey JF, Specht LM, Thompson MS. Cementless Acetabular Fixation With and Without Screws Analysis of Stability and Migration. J Arthroplasty. 2009 Mar 19

7. Wasielewski RC, Cooperstein LA, Kruger MP, Rubash HE. Acetabular anatomy and the transacetabular fixation of screws in total hip arthroplasty. J Bone Joint Surg Am. 1990 Apr; 72(4): 501-8

8. Archibeck MJ, Showalter D, Kavanaugh TS, Camarata D, White RE, Jr. A comparison of cementless acetabular components of the same design: spiked versus supplemental screws. J Arthroplasty. 2003 Oct; 18(7 Suppl 1): $122-5$

9. Kwong LM, O'Connor DO, Sedlacek RC, Krushell RJ, Maloney WJ, Harris WH. A quantitative in vitro assessment of fit and screw fixation on the stability of a cementless hemispherical acetabular component. J Arthroplasty. 1994 Apr; 9(2): 163-70

10. Thanner J, Karrholm J, Herberts P, Malchau H. Hydroxyapatite and tricalcium phosphate-coated cups with and without screw fixation: a randomized study of 64 hips. J Arthroplasty. 2000 Jun; 15(4): 405-12

11. Udomkiat P, Dorr LD, Wan Z. Cementless hemispheric porous-coated sockets implanted with press-fit technique without screws: average ten-year follow-up. J Bone Joint Surg Am. 2002 Jul; 84-A(7): 1195-200

12. Schmalzried TP, Wessinger SJ, Hill GE, Harris WH. The Harris-Galante porous acetabular component press-fit without screw fixation. Five-year radiographic analysis of primary cases. J Arthroplasty. 1994 Jun; 9(3): 235-42

13. Torga Spak R, Stuchin SA. Cementless porous-coated sockets without holes implanted with pure press-fit technique. J Arthroplasty. 2005 Jan; 20(1): 4-10

14. Healy WL, Iorio R, Lemos MJ, Patch DA, Pfeifer BA, Smiley PM, Wilk RM. Single Price/Case Price Purchasing in orthopaedic surgery: experience at the Lahey Clinic. J Bone Joint Surg Am. 2000 May; 82(5): 607-12

15. Wilkinson JM, Hamer AJ, Elson RA, Stockley I, Eastell R. Precision of EBRA-Digital software for monitoring implant migration after total hip arthroplasty. J Arthroplasty. 2002 Oct; 17(7): 910-6
16. Phillips NJ, Stockley I, Wilkinson JM. Direct plain radiographic methods versus EBRA-Digital for measuring implant migration after total hip arthroplasty. J Arthroplasty. 2002 Oct; 17(7): 917-25

17. Ilchmann T, Kesteris U, Wingstrand H. EBRA improves the accuracy of radiographic analysis of acetabular cup migration. Acta Orthop Scand. 1998 Apr; 69(2): 119-24

18. Krismer M, Bauer R, Tschupik J, Mayrhofer P. EBRA: a method to measure migration of acetabular components. J Biomech. 1995 Oct; 28(10): 1225-36

19. Ochs U, Ilchmann T, Ochs BG, Marx J, Brunnhuber K, Luem M, Weise K. EBRA migration patterns of the Plasmacup with ceramic or polyethylene inserts: a randomised study. Z Orthop Unfall. 2007 Sep-Oct; 145 Suppl 1(S204)

20. Langton DJ, Sprowson AP, Mahadeva D, Bhatnagar S, Holland JP, Nargol AV. Cup Anteversion in Hip Resurfacing: Validation of EBRA and the Presentation of a Simple Clinical Grading System. J Arthroplasty. 2009 Dec 17

21. Klestil T, Biedermann R, Kruger A, Gfoller P, Schmoelz W, Rangger C, Krismer M, Blauth M. Cementless hemiarthroplasty in femoral neck fractures: evaluation of clinical results and measurement of migration by EBRA-FCA. Arch Orthop Trauma Surg. 2006 Aug; 126(6): 380-6

22. Ilchmann T, Gelzer JP, Winter E, Weise K. Acetabular reconstruction with the Burch-Schneider ring: an EBRA analysis of 40 cup revisions. Acta Orthop. 2006 Feb; 77(1): 79-86

23. DeLee JG, Charnley J. Radiological demarcation of cemented sockets in total hip replacement. Clin Orthop Relat Res. 1976 Nov-Dec; 121): 20-32

24. Ilchmann T, Mjoberg B, Wingstrand H. Measurement accuracy in acetabular cup wear. Three retrospective methods compared with Roentgen stereophotogrammetry. J Arthroplasty. 1995 Oct; 10(5): 636-42

25. Schmalzried TP, Shepherd EF, Dorey FJ, Jackson WO, dela Rosa M, Fa'vae F, McKellop HA, McClung CD, Martell J, Moreland JR, Amstutz HC. The John Charnley Award. Wear is a function of use, not time. Clin Orthop Relat Res. 2000 Dec; 381): 36-46

26. Morscher EW, Widmer KH, Bereiter H, Elke R, Schenk R. [Cementless socket fixation based on the "press-fit" concept in total hip joint arthroplasty]. Acta Chir Orthop Traumatol Cech. 2002 69(1): 8-15

27. Rohrl SM, Nivbrant B, Strom H, Nilsson KG. Effect of augmented cup fixation on stability, wear, and osteolysis: a 5-year follow-up of total hip arthroplasty with RSA. J Arthroplasty. 2004 Dec; 19(8): 962-71

28. Won CH, Hearn TC, Tile M. Micromotion of cementless hemispherical acetabular components. Does press-fit need adjunctive screw fixation? J Bone Joint Surg Br. 1995 May; 77(3): 484-9

29. Schmalzried TP, Guttmann D, Grecula M, Amstutz HC. The relationship between the design, position, and articular wear of acetabular components inserted without cement and the development of pelvic osteolysis. J Bone Joint Surg Am. 1994 May; 76(5): 677-88

Received: April 132010 / Accepted: May 24, 2010

\section{Address for correspondence:}

Marcus Jäger, $\mathrm{MD} / \mathrm{PhD}$

Deputy Chief, Department of Orthopaedics,

Heinrich-Heine University Medical School

Moorenstraße 5, 40225 Duesseldorf, Germany

Phone: $+49(0) 2118118314$

Fax: $\quad+49(0) 2118116281$

E-mail: Jaeger@med.uni-duesseldorf.de Christoph.Zilkens@med.uni-duesseldorf.de 